\title{
Identification and characterization of hybrids of Acipenser ruthenus and Acipenser baerii (Actinopterygii, Acipenseriformes) from the Irtysh River
}

\author{
Elizaveta Liberman ${ }^{1}$, Andrey Chemagin ${ }^{1}$, \\ Gleb Volosnikov', Oxana Zhigileva ${ }^{2}$
}

1 Tobolsk complex scientific station UrB RAS, 16 Osipova St., Tyumen region, Tobolsk, 626150, Russia 2 Department of Ecology and Genetics, Tyumen State University, 6 Volodarskogo St., Tyumen, 625003, Russia

Corresponding author: Andrey Chemagin (chemaginaa@yandex.ru)

Academic editor: R. Yakovlev | Received 12 April 2021 | Accepted 22 August 2021 | Published 4 October 2021

http://zoobank.org/4A9B3D01-2C0D-4E7F-B60C-6DCF5173D2FF

Citation: Liberman E, Chemagin A, Volosnikov G, Zhigileva O (2021) Identification and characterization of hybrids of Acipenser ruthenus and Acipenser baerii (Actinopterygii, Acipenseriformes) from the Irtysh River. Acta Biologica Sibirica 7: 261-282. https://doi.org/10.3897/abs.7.e67157

\begin{abstract}
Two sturgeon species, Acipenser ruthenus (Linnaeus, 1758) and Acipenser baerii (Brandt, 1869), inhabit the Irtysh basin. In 2018, we received some "atypical" specimens of sturgeon, which were similar to $A$. ruthenus, but had a number of pronounced external differences. The hybrids A. ruthenus $\times A$. baerii, named "oster", can sometimes be caught in natural habitats in the Ob and the Yenisei rivers. Despite the development of methods for the genetic identification of sturgeons, the molecular genetic characteristics of the hybrids of $A$. baerii and A. ruthenus have not been carried out. The purpose of this study is to develop a complex of morphological and genetic characters to identify the hybrid of A. ruthenus and $A$. baerii from the Irtysh River. We used a complex of morphological and genetic methods to compare the putative hybrids with parental species The putative hybrids were similar to $A$. ruthenus in the number of dorsal scutes, the number of rays in the dorsal and anal fins, the structure of stamens on the first gill arch, and the presence of fringe on the tendrils. The hybrids were similar to $A$. baerii in size and weight values, the structure of dorsal scutes, the number of lateral and ventral scutes, and the number of gill rakers on the first gill arch. Genotyping of putative hybrids by using the Inter Simple Sequence Repeat (ISSR) markers revealed the presence of sites characteristic of both parental species. The fragment of the control region of mitochondrial DNA in the hybrids matched to
\end{abstract}

Copyright Elizaveta Liberman et al. This is an open access article distributed under the terms of the Creative Commons Attribution License (CC BY 4.0), which permits unrestricted use, distribution, and reproduction in any medium, provided the original author and source are credited. 
that of A. baerii that allowed us to identify females of A. baerii as maternal individuals of the hybrids. Possible causes and factors promoting interspecific hybridization of A. ruthenus and A. baerii were studied. This is the first described fact of the appearance of sturgeon hybrids in the Ob-Irtysh basin. It is necessary to continue monitoring studies to identify the number of these hybrids in the ecological system of the Irtysh River. The data set of morphological characters and genetic methods can be used to identify the hybrids of A. ruthenus and A. baerii.

\section{Keywords}

ISSR, hybridization, morphometric, mtDNA, Acipenseridae, Ob-Irtysh basin

\section{Introduction}

The hybridization and introgression of species have increased significantly throughout the world due to the movement of organisms and modifications of their habitat as a result of an anthropogenic impact (Sales et al. 2018; Uemura et al. 2018). This also applies to sturgeons (Lagunova 1999; Ludwig et al. 2009; Dudu et al. 2011). On the one hand, hybridization contributes to the extinction of many species in direct and indirect ways (Borkin and Litvinchuk 2013; Chafin et al. 2019; Ramoejane et al. 2019); on the other hand, natural hybridization plays an important role in the evolution of many plant and animal taxa (Allendorf et al. 2001; Mallet 2007; Schwenk et al. 2008). In fish, natural hybridization is quite common (Allendorf et al; 2001). It can occur even between species, in which divergence occurred at least five million years ago (Smith 1992; Borkin and Litvinchuk 2013). However, within the order Acipenseriformes, hybridization is possible even between species divergenced 184.4 million years ago (Káldy et al. 2020). In addition, various fish species are cultivated worldwide outside their natural habitat (Allendorf et al. 2001; Dudu et al. 2011; Uemura et al. 2018), with a possible escape into natural water bodies with fish-breeding farms or by illegal fish stocking (Atalah, Sanchez-Jerez 2020; Nyeste et al. 2020). It is worth noting that freshwater fish outperform marine species in the frequency of hybridization (Hubbs 1955). There is a risk of losing the reproductive efforts of natural population due to hybridization (Allendorf et al. 2001). Interspecific hybridization is a common phenomenon among sturgeons, which is often used in aquaculture (Zhang et al. 2013). However, in vivo, it can contribute to the extinction and disappearance of native species (Dudu et al. 2011). Nevertheless, sturgeons may have natural hybrid zones in rivers (Allendorf et al. 2001; Jordan et al. 2019). Therefore, for the conservation and rational use of biological resources of sturgeons, monitoring of their populations is necessary (Allendorf et al. 2001). That implies the presence of reliable and easy-to-use genetic markers (Allendorf et al. 2001; Dudu et al. 2011; Jordan et al. 2019). In addition, the use of DNA methods to identify species is also becoming relevant for food quality control and confirmation of the fishery products value (Porto-Foresti et al. 2013; Ardura et al. 2010; Fernandes et al. 2017; Sriphairoj et al. 2018). 
Many researchers have often used the combination of the morphological and molecular methods to identify various species of aquatic organisms (Porto-Foresti et al. 2013; Sales et al. 2018; Ha et al. 2018; Begum et al. 2018; Jordan et al. 2019) when the use of each of the methods separately cannot give an exact result in determining the species. For example, in the study of many species of freshwater copepods of the family Diaptomidae (Begum et al. 2018), their taxonomic identification was difficult due to high morphological similarities and not significant differences in key characteristics among individuals of different genera. This in turn determines (Sriphairoj et al. 2018) the need for reliable species diagnostic molecular markers to identify species groups having overlapping morphological characteristics. The same situation is observed in the hybrids of sturgeons, which inherit morphological characteristics from parent species, in this regard, the identification of a particular individual as a hybrid, based only on morphology, is not reliable enough, especially when studying juvenile fish (Dudu et al. 2011).

Due to the high commercial value of sturgeon fish, as well as their frequent use in aquaculture, the methods of molecular genetic identification of species for this group of fish are well developed. Microsatellites, allozyme markers, and gene fragments of mitochondrial DNA (mtDNA) are used to certify sturgeon fishes, to monitor aquaculture herds, and to identify the origin of domesticated fish (Shishanova 2013; Shishanova and Pavlov 2013; Barmintseva and Mugue 2018), as well as to analyze museum exhibits and archaeological remains (Chassaing et al. 2010). Mugue and collaborators proposed a DNA identification system for eight species of sturgeons based on polymorphism of the control region of mtDNA (Mugue et al. 2008). MtDNA markers have also been successfully used to study genetic polymorphism and phylogeography of natural populations of Danube sturgeon Acipenser gueldenstaedtii (Brandt and Ratzeburg 1833), Amur sturgeon Acipenser schrenckii (Brandt, 1869), Siberian sturgeon Acipenser baerii (Brandt 1869) (Shedko et al. 2015; Barmintseva and Mugue 2017), and Sterlet sturgeon Acipenser ruthenus (Linnaeus, 1758) (Pobedintseva et al. 2019).

However, the matrilineal inheritance does not allow mtDNA to be used to identify interspecific hybrids (Timoshkina et al. 2011). For this purpose, multilocus markers such as RAPD (Random Amplified Polymorphic DNA) can be used. Their use to characterize the offspring obtained by artificial hybridization of three sturgeons species: A. schrenckii, A. baerii, and A. ruthenus, allowed detecting DNA markers of both parent species in the hybrid genome (Rozhkovan et al. 2008). The dependence of the frequency of occurrence of certain DNA fragments depending on the direction of crossings was also established (Rozhkovan et al. 2008).

Only two sturgeon species, A. ruthenus and A. baerii, inhabit the Lower Irtysh basin. A. ruthenus belongs to the first category of rarity (some populations of a common species, which are under the threat of extinction); its catch is permitted only for scientific research and control purposes. The West Siberian population of A. baerii is on the verge of extinction (the second category of rarity); its catch is prohibited throughout the Ob-Irtysh basin (Bol'shakov et al. 2004). 
During the summer-autumn period of 2018, we received information about the capture of "atypical" specimens of sturgeon, which were similar to A. ruthenus but had a number of pronounced external differences; in particular, wider lateral scutes, a larger size of the spine of the dorsal scutes in comparison with A. ruthenus that inhabits the Irtysh River. In a number of characters, the "atypical" specimens were similar to both $A$. baerii and $A$. ruthenus. The combination of characters of different species in one individual serves as the basis for the assumption of their hybrid origin (Lima et al. 2019).

Despite the development of methods for the genetic identification of sturgeons, the molecular genetic characteristics of the hybrids of $A$. baerii and A. ruthenus have not been carried out. Meanwhile, these hybrids, named "oster", can sometimes be caught in natural habitats in the $\mathrm{Ob}$ and Yenisei rivers. In addition, hybrids are regarded as a potential promise in aquaculture.

The purpose of this study is to develop a complex of morphological and genetic characters to identify the hybrid of $A$. ruthenus and $A$. baerii when studying the state of populations of these fish species from the Irtysh River.

\section{Material and methods}

\section{Sampling and morphologic studies}

We studied fish of the Acipenseridae family, which were collected in the lower reaches of the Irtysh River within the Tobolsk $58^{\circ} 8^{\prime} 54.63^{\prime \prime} \mathrm{N}, 68^{\circ} 14^{\prime} 31.42^{\prime \prime E}$ and Uvat districts $58^{\circ} 43^{\prime} 26.36^{\prime \prime} \mathrm{N}, 68^{\circ} 41^{\prime} 10.45^{\prime \prime} \mathrm{E}$ of the Tyumen region (Western Siberia, Russia) (Fig. 1).

We used fixed and rafted different-mesh nets with a mesh of $24-38 \mathrm{~mm}$ from 5 -meter sections. The length of the fixed net was $40 \mathrm{~m}$, the rafted net was $60 \mathrm{~m}$, and the height was $2 \mathrm{~m}$. For genetic studies, we used live 17 specimens of $A$. ruthenus, including 5 individuals of putative hybrids with visually distinct characteristics from A. ruthenus. For comparison, we used fixed 11 individuals of $A$. baerii collected in the same area and provided for judicial ichthyologic expertise by the Ministry of Internal Affairs of the Tyumen Region. For statistical analysis of meristic characteristics, 129 individuals of $A$. ruthenus collected from this section of the river in 2017 were additionally investigated. The age of the fish, their meristic and morphological characteristics were studied in accordance with generally accepted methods (Pravdin 1966; Kafanova 1984; Kottelat and Freyhof 2007). We determined the age by counting annual rings observed on polished cuts of marginal rays of pectoral fins (Kafanova 1984). Photos were taken using the LOMO MSP-1 binocular and the Nikon D5100 camera (macro mode). The size and weight values of the alleged hybrids were compared with the indicators of individuals of $A$. ruthenus, which were collected in the Irtysh River in 2017. We compared also the meristic characteristics: 
the number of dorsal scutes, lateral scutes, abdominal scutes, the number of rays in the dorsal and anal fins, as well as the number of gill rakers on the first gill arch.

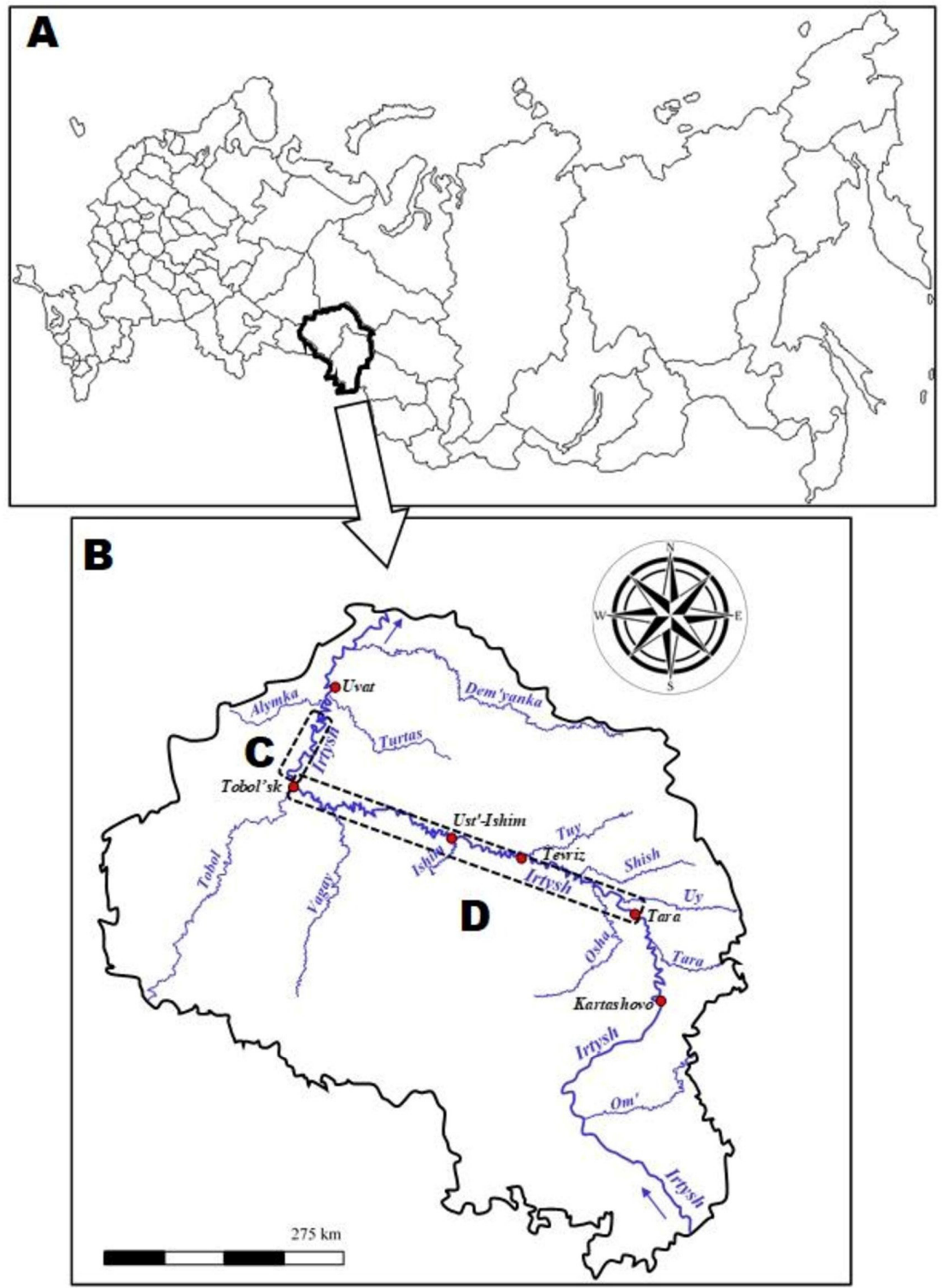

Figure 1. Map-scheme of the research area: A - Northern Eurasia, B - the Irtysh River with main tributaries, $\mathbf{C}$ - zone of spawning areas of Acipenser ruthenus (dotted line), D zone of spawning areas of Acipenser baerii (dotted line), arrows - the direction of the river, red points - hydrometeorological posts. 


\section{Hydrological analysis}

To detect factors of the natural origin of these hybrids, we used data on the water level of the river during the spawning period of the studied fish species (from April 20 to June 25). The analysis of the hydrological situation in the study area was carried out using data from hydrological posts on the Irtysh River (Fig. 1). We analyzed the average water level during the long-term period (2006-2019) and the period of the origin of the hybrids (2017). The significance of the difference was determined using the Kruskal-Wallis test since there was no normal distribution in the groups of observation of these water levels. The year of origin of the hybrids was established by determining the age of these individuals by annual rings on the cut of the marginal ray of the pectoral fin. Individuals in 2018 were identified as at the age of 1-year old.

\section{DNA extraction and genetic studies}

For genetic studies, skeletal muscle tissue samples were taken from all the individuals of the fish. Total genomic DNA was extracted from skeletal muscle tissue fixed in $70 \%$ ethanol using the technique of alkaline lysis (Bender et al. 1983). For genotyping, two types of markers - a part of the mtDNA control region and Inter Simple Sequence Repeat (ISSR) were used. Amplification of ISSR was carried out using 25 $\mu \mathrm{L}$ of reaction mixture containing PCR buffer $(0.01 \mathrm{M}$ Tris- $\mathrm{HCl}, 0.05 \mathrm{M} \mathrm{KCl}, 0.1 \%$ triton X-100), $4 \mathrm{mM} \mathrm{MgCl} 2,0.2 \mathrm{mM}$ of each dNTPs, $1 \mu \mathrm{L}$ of total DNA solution, 2.5 $\mathrm{mM}$ of primer and 0.2 unit. $\mu \mathrm{L}-1$ of Taq-polymerase ("Fermentas") in the following mode: $94^{\circ} \mathrm{C}-7 \mathrm{~min}$; then $94^{\circ} \mathrm{C}-30 \mathrm{~s}, 52(56)^{\circ} \mathrm{C}-45 \mathrm{~s}, 72^{\circ} \mathrm{C}-2$ min $(40$ cycles); $72^{\circ} \mathrm{C}-7 \mathrm{~min}$. We used four ISSR primers: (AG)8C (UBC808), (AG)8G (UBC809), (AG)8T (UBC807), and (AC)8T (UBC825).

To study the polymorphism of the mtDNA control region, primer sequences and amplification protocols proposed by Mugue et al. (2008) were used. Polymerase chain reaction (PCR) products were separated on a $2 \%$ agarose gel. The sizes of the fragments were determined using 1000/50 DNA molecular weight markers. Electrophoretic gels were documented using VersaDoc system (Bio-Rad).

\section{Data analysis}

Statistical analysis was performed by STATISTICA 10.0 (StatSoft, USA). The Tukey Post Hoc test for unequal samples (Unequal N HSD) was used to assess the significance of differences in morphological characteristics. 


\section{Results}

\section{Morphological characteristics of the hybrids}

In individuals of the hybrids were detected wider lateral scutes and a larger spine of dorsal scutes compared to individuals of A. ruthenus of the Irtysh River (Fig. 2a, d).

When considering the form of the dorsal scutes of the hybrid, there was a similarity with the dorsal scutes of juvenile A. baerii (Fig. 2c). The height and form of the spine of the dorsal scutes of the hybrids took an intermediate position between A. baerii and A. ruthenus (Fig. 2c-e). Despite the similar shape of the dorsal scutes of $A$. baerii and the hybrids, there was a difference in the particular arrangement of the scutes themselves relative to each other. In particular, the dorsal scutes of $A$. ruthenus and the hybrids were closer with each other, forming a continuous row, while in A. baerii there were gaps between them (Fig. 3) (Gnedov and Kaizer 2013).

The hybrids presented in the study were 1-year old. The average body weight was $144 \mathrm{~g}$; the minimum value for this indicator was 122 , a maximum of $160 \mathrm{~g}$. As a result of a comparative analysis with the body weight of $A$. ruthenus individuals at the age of 1-year old, collected on the same location of the Irtysh River in 2017, it was found that $A$. ruthenus body weight was significantly lower and varied between 54 and $142 \mathrm{~g}$; on average, this indicator was $84.7 \mathrm{~g}$. The average absolute body length of the hybrids was $37.7 \mathrm{~cm}$, but $A$. ruthenus was $29 \mathrm{~cm}$.

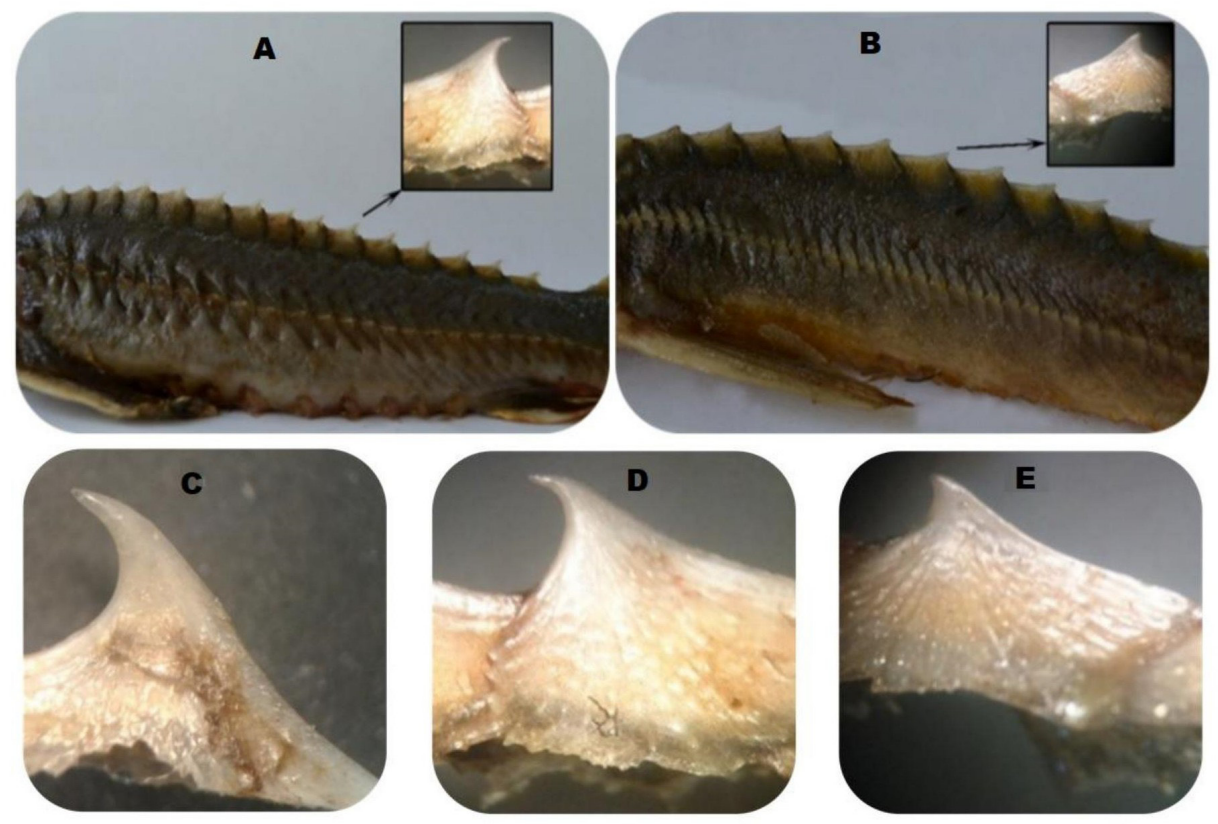

Figure 2. Body of putative hybrids (A), Acipenser ruthenus (B), and photography of dorsal scutes of Acipenser baerii (C), putative hybrids (D) and Acipenser ruthenus (E). 
To identify the hybrids, the values of their meristic characteristics were compared with the individuals of $A$. ruthenus and A. baerii of the Irtysh River (Fig. 4).

The statistical analysis of the meristic characteristics of the hybrid and its parent species, $A$. baerii, and $A$. ruthenus, indicated the significant differences in the number of dorsal scutes $(\mathrm{P}<0.001)$. The hybrids and $A$. baerii had 16 and 13.46 dorsal scutes, respectively. The average number of dorsal scutes in A.ruthenus was 14.17 and differed from that of the hybrids $(\mathrm{P}<0.05)$. A statistically significant difference $(\mathrm{P}<0.001)$ in the number of lateral scutes was found between the hybrids $(48.2)$ and A. baerii (45.82) in comparison with $A$. ruthenus (62.83). Similarly, the difference (P $<0.001)$ was established in the number of ventral scutes; this value averaged 9.8 in the hybrids, 9.82 - in A. baerii, and 14.15 - in A. ruthenus. A significant difference between the hybrids and $A$. baerii, as well as parental species from each other, was noted by the number of gill rakers on the first gill arch $(\mathrm{P}<0.05)$. The mean value of this sign was 25.6 in the hybrids, 23.36 - in A. baerii, and 18.77 - in A. ruthenus. No differences were noted in other cases.

\section{Hydrological analysis}

Fig. 1 shows a map of the hydrological posts and the distribution of spawning areas of $A$. ruthenus and $A$. baerii. When constructing the water level diagrams from the presented hydrological posts, it was found that the water level in the spawning areas, upstream and downstream from them exceeded the average annual level over a 13-years period in 2017, and in some observations was the maximum (Fig. 5).

The statistical analysis showed that the water level in the year of origin of the hybrids did not differ significantly from the long-term average (2006-2019) in the posts of Tara ( $\mathrm{df}=82, \mathrm{P}=0.448)$, Kartashovo and Ust'-Ishim ( $\mathrm{df}=82, \mathrm{P}=1.000)$, Tevriz $(\mathrm{df}=82, \mathrm{P}=0.511)$, the posts of Tobol'sk $(\mathrm{df}=80, \mathrm{P}=0.230)$ and Uvat $(\mathrm{df}=$ $78, \mathrm{P}=0.275)$.
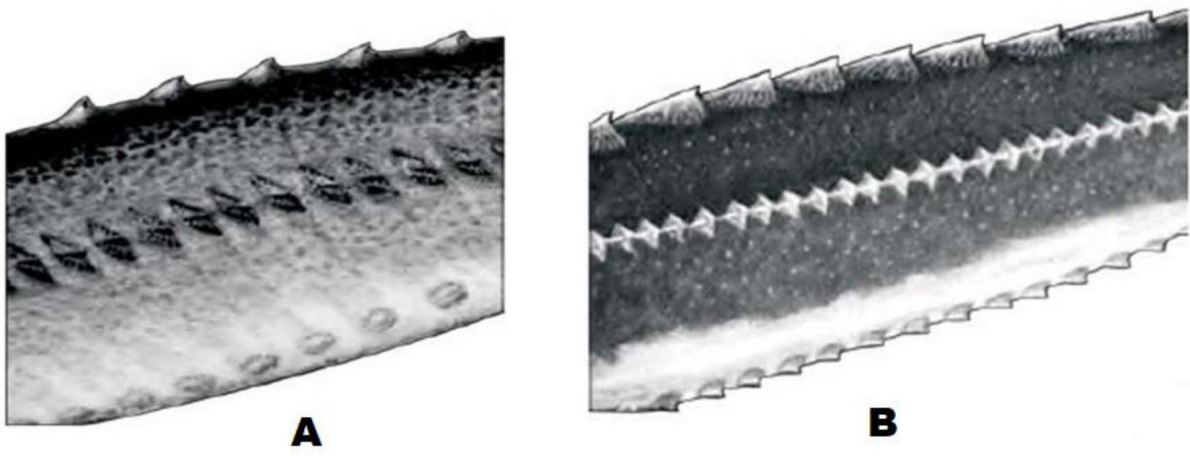

Figure 3. Position dorsal scutes of Acipenser baerii (A), and Acipenser ruthenus (B) (by Gnedov and Kaizer 2013). 

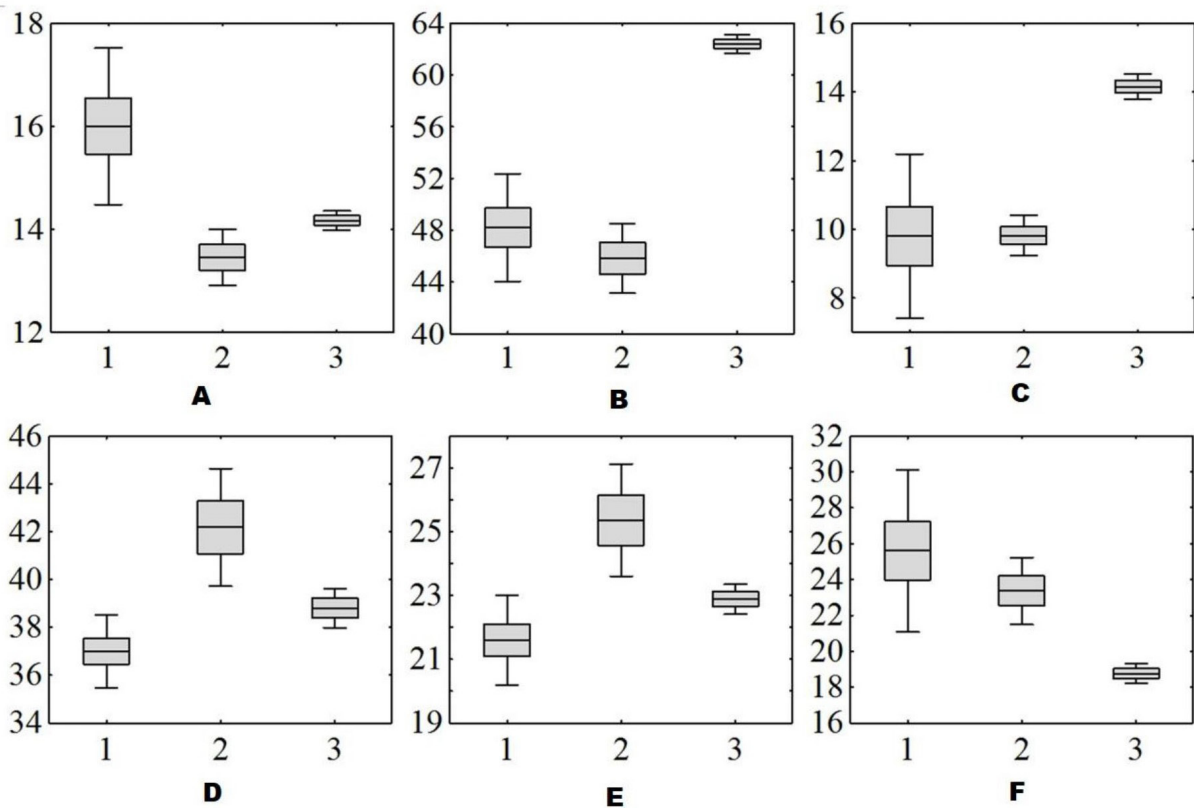

Figure 4. Meristic characteristics of putative hybrids (1) and parental species Acipenser baerii (2) and Acipenser ruthenus (3): $\mathbf{A}$ - number of dorsal scutes, $\mathbf{B}$ - number of side scutes, $\mathbf{C}$ - number of ventral scutes, $\mathbf{D}$ - number of rays in dorsal fin, $\mathbf{E}$ - number of rays in anal fin, $\mathbf{F}$ - number of gill rakers on the first gill arch.

\section{Genetic characteristics of the hybrids}

Genotyping of sturgeons from the Irtysh River according to the sequence of a fragment of the mtDNA control region showed the absence of amplification products in hybrid individuals in the reaction with primers specific for A. ruthenus (RutF / AHR) and its presence in the reaction with primers specific for A. baerii (ABF / AHR) (Fig. 6).

In ISSR patterns obtained using the UBC808 primer, DNA fractions of 120 and $370 \mathrm{bp}$ were the same in putative hybrids and A. ruthenus individuals; fragments of 400 and $350 \mathrm{bp}$ in size made the putative hybrid individuals closer to A. baerii. ISSR patterns of the putative hybrids differed both from the patterns of $A$. ruthenus and A. baerii (Fig. 7). They contained not only sets of bands characteristic of both parental species but also additional bands (Table 1). The appearance of additional DNA fragments in the RAPD profiles of the hybrid offspring of A. baerii and A. ruthenus was also noted in a study by Rozhkovan et al. (2008). 
Table 1. The presence of the Inter Simple Sequence Repeat (ISSR) markers obtained using primer UBC808 in sturgeon from the Irtysh River

\begin{tabular}{lccc}
\hline Fragment length, bp & A. baerii & Hybrids & A. ruthenus \\
\hline 490 & + & - & - \\
400 & + & + & - \\
370 & - & + & + \\
350 & + & + & - \\
320 & - & + & - \\
300 & + & - & - \\
270 & + & + & + \\
240 & + & + & - \\
120 & - & + & + \\
\hline
\end{tabular}

\section{Discussion}

When studying the morphological characteristics of $A$. ruthenus, A. baerii and putative hybrids, it is necessary to take into account that the range of variation in the number of dorsal scutes in A. ruthenus in different parts of the distribution area is 11-18 (Reshetnikov 2003; Gnedov and Kaizer 2013). Thus, it cannot say that the hybrids differ from $A$. ruthenus according to the number of dorsal scutes, although individuals of $A$. baerii have the same value of this sign. However, in our study, statistical analysis showed the presence of significant differences between the hybrids and parent species. Gnedov and Kaizer (Gnedov and Kaizer 2013) considered that the most specific sign is the number of lateral scutes since the ranges of variation in the number of dorsal and ventral scutes often overlap for different species of sturgeons. When analyzing A. ruthenus of the Irtysh River, individuals were found with a minimum number of lateral scutes of 49 , and there were hybrid individuals with a value of this sign $<49$. Some researchers (Reshetnikov 2003; Parenskiy et al. 2008) noted that the number of lateral scutes $<50$ was found in the hybrids of $A$. ruthenus with other sturgeons. The smaller number of lateral scutes for the hybrids is explained by the larger size of the plates than in A. ruthenus (Fig. 2, 3).

The number of ventral scutes in the hybrids turned out to be more similar to $A$. baerii than to $A$. ruthenus, the limits of variation of this sign in $A$. ruthenus are from 10 to 20 (Reshetnikov 2003; Gnedov and Kaizer 2013). Thus, a comparison of this characteristic in the hybrids with the literature data and the fish studied confirms doubts about the belonging of the hybrids to A. ruthenus.

The range of number of rays in the dorsal fin is similar in A. baerii and A. ruthenus was 35-49 and 32-45, respectively. In hybrids, this sign varied from 35 to 38. If we take into account that fluctuations in the number of rays in the dorsal fin in 
A. ruthenus are permissible from 32 to 49 (Reshetnikov 2003; Gnedov and Kaizer 2013), then the hybrids are similar in this sign to both A. ruthenus and A. baerii. In this regard, the analysis of this trait is also not exhaustive in identifying the species of the studied sturgeons.
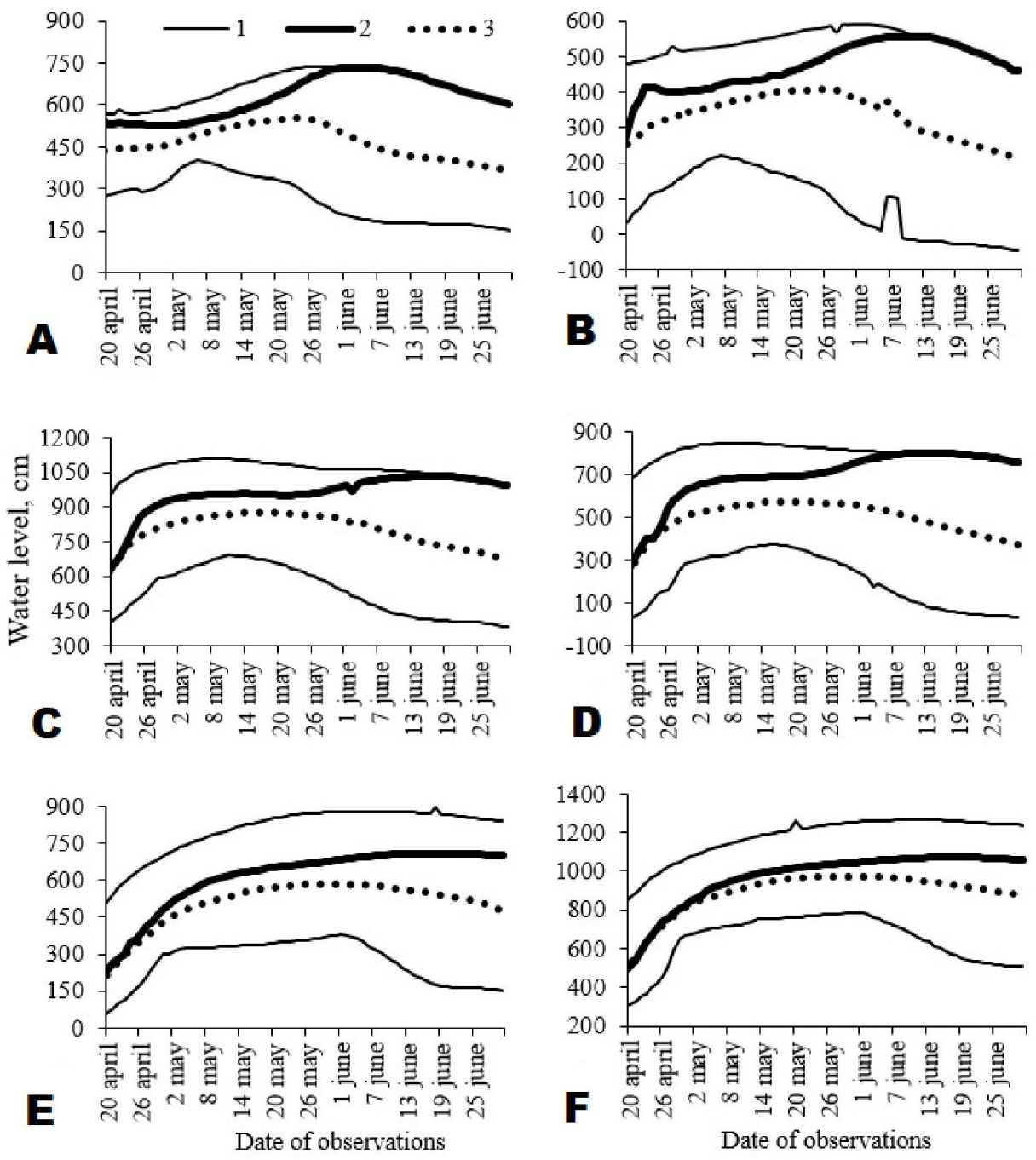

Figure 5. Water levels according to hydrometeorological posts are upstream and downstream and in the area of spawning sites of Acipenser baerii and Acipenser ruthenus in the Irtysh River: A - Tara, B - Kartashovo, C - Tevriz, D - Ust'-Ishim, E - Tobol'sk, F - Uvat. 1 - amplitude min-max, 2 - water level 2017 year, 3 - average water level (2006 -2018). 


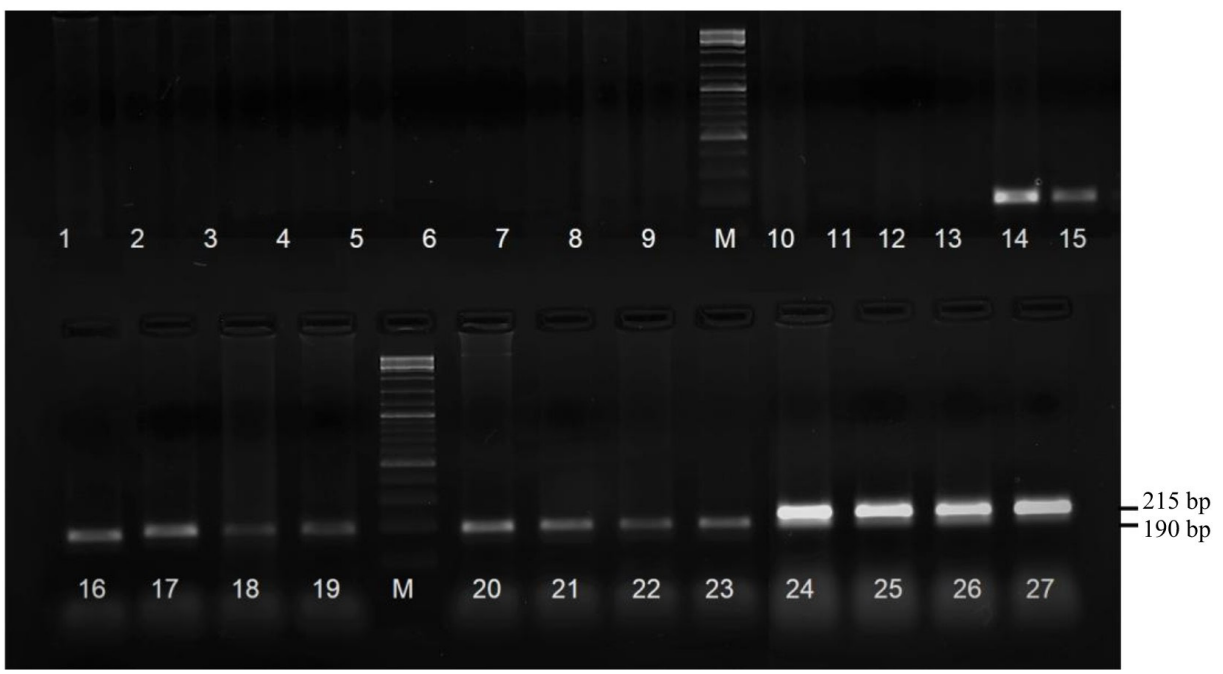

Figure 6. Electrophoregram of PCR products of the mtDNA control region of sturgeon from the Irtysh River: tracks 1-23 with primers species-specific for A. ruthenus (RutF/ AHR), 1-9 - Acipenser baerii, 10-13 - putative hybrids, 14-23 - Acipenser ruthenus; 24-27 - hybrids with species-specific primers for A. baerii (ABF/AHR). There is product amplification of speciesspecific for A. ruthenus fragment (190 bp) in A. ruthenus samples (tracks 14-23), but it absence in A. baerii (tracks 1-9) and hybrids (tracks 10-13). We can see amplification of $215 \mathrm{bp}$ fragment species-specific for A. baerii in hybrids (tracks 24-27). M - DNA length marker 100-1500 bp. 2\% agarose gel, ethidium bromide.

The largest average value of the number of rays in the anal fin was 25.4 in $A$. baerii, these values in $A$. ruthenus and the hybrids were 22 and 21.6, respectively. The difference was observed only in ranges of variation of characteristics that partially overlap. In A. baerii, the number of rays in the anal fin ranged from 22 to 30; in A. ruthenus and the hybrids, it was 18-27 and 20-23, respectively. As follows from the data (Reshetnikov 2003; Gnedov and Kaizer 2013), this sign cannot be key-sign because the limits of variation of the indicator of this trait overlap in all species of the analyzed fish. The same is true for the number of gill rakers in the first gill arch (Gnedov and Kaizer 2013).

It is worth noting that the hybrids we found in the Irtysh River are close to the individuals of hybrids A.baerii x A. ruthenus which obtained under artificial conditions by some meristic characters (Chebanov et al. 2017). However, the values of these indicators in the caught fish are slightly less than in the hybrids of artificial origin, excluding the average number of dorsal scutes (Chebanov et al. 2017): the number of dorsal scutes 16 and 14.8, the number of lateral scutes - 48.2 and 49.3, the number of ventral scutes 9.8 versus 12.8 , the number of rays in the dorsal fin against 37 and 42.6, the number of rays in the anal fin 21.6 and 24.2, the number of gill rakers on the first branchial arch 25.6 and 28.2 respectively. 


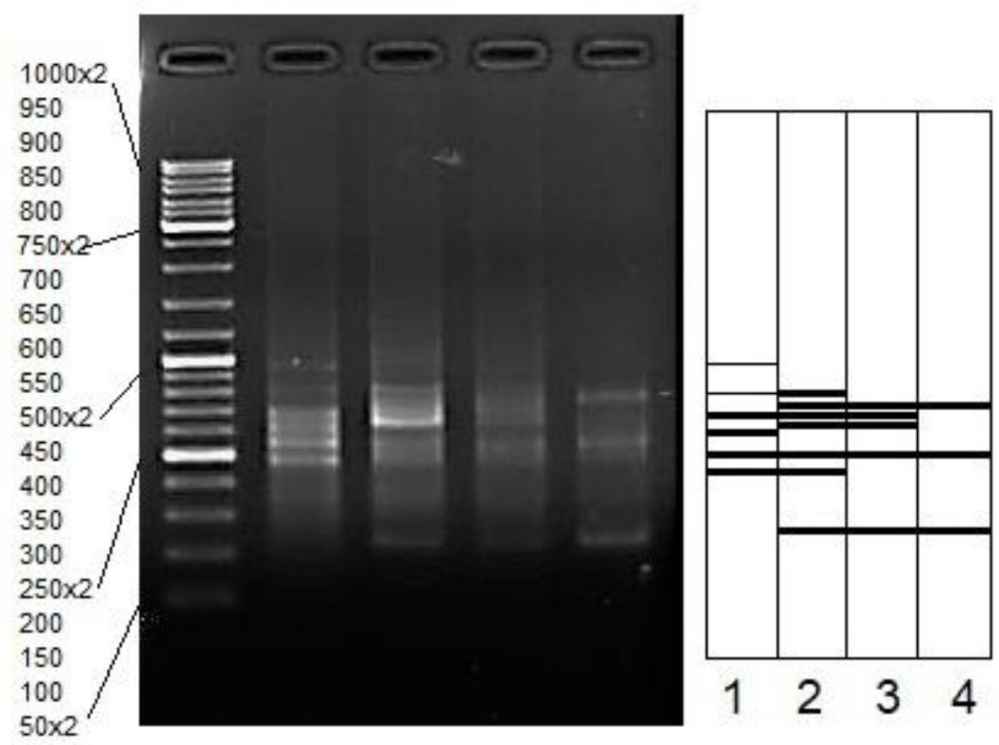

Figure 7. Electrophoregram of the Inter Simple Sequence Repeat (ISSR) patterns of sturgeon fish with primers UBC808: 1 - Acipenser baerii, 2, 3 - putative hybrids of $A$. baerii $\times A$. ruthenus, 4 - Acipenser ruthenus. M - DNA length marker 1000/50 (Diaem). Fragments size is indicated. $2 \%$ agarose gel, ethidium bromide.

In the age group 1-year-old, the phenomenon of heterosis, i.e. The excess of the mass and body length of the hybrids over the parental species A. ruthenus was noted in our study by 1.7 and 1.3 times, as well as in individuals of artificial origin by 2.4 and 1.5 times, respectively (Chebanov et al. 2017).

An additional argument in favor of the possible belonging of hybrid individuals to the A. ruthenus species is the presence of fringed antennae and non-fan-shaped gill stamens, which is typical for $A$. ruthenus and excludes the belonging of the analyzed hybrid individuals to A. baerii. In the analysis of meristic and key-species characteristics, it was found that hybrid individuals of sturgeons from the Irtysh River were similar to both $A$. ruthenus and $A$. baerii. This feature does not allow us to identify the hybrids and unambiguously attribute them to any species, it only provides a basis for further deeper analysis (Lima et al. 2019), including genetic, in order to confirm or refute the hybrid origin of the studied individuals of fish.

As a result of genetic analysis, it was found that these individuals from Acipenseridae family were indeed of hybrid origin, and for all of them, A. baerii was identified as maternal $-\stackrel{+}{A}$. baerii $\times \lesssim A$. ruthenus. Identification of hybrids using morphological characteristics usually suggests that hybrid will be phenotypically intermediate in relation to parental species, often it is not (Borkin and Litvinchuk 2013) because hybrids sometimes show a mosaic of phenotypes of parental species 
(Allendorf et al. 2001). Moreover, not all morphologically intermediate individuals are hybrids (Borkin and Litvinchuk 2013). This pattern, based on the morphological characteristics of sturgeons, A. ruthenus and A. baerii, was also shown in our study. Genotyping of fish using nuclear DNA markers also confirmed the hybrid nature of putative hybrids specimens. The combined use of nuclear and mitochondrial DNA markers not only confirms the hybrid nature of the putative hybrids from the Irtysh River but also allows identifying $A$. baerii females as maternal individuals of these hybrids. Therefore, the use of morphological characters for identifying hybrids is possible only in combination with DNA-based methods (Dudu et al. 2011).

In natural habitats, interspecific hybridization is prevented by a number of different (precopulation and postcopulation) reproductive barriers (Havelka et al. 2016). However, anthropogenic factors can affect natural precopulation reproductive barriers (Borkin and Litvinchuk 2013; Chafin et al. 2019; Ramoejane et al. 2019), reducing isolation of gametes and, therefore, stimulating interspecific hybridization (Lagunova 1999; Dudu et al. 2011; Chafin et al. 2019). This is true for the order Acipenseriformes demonstrating the amazing ease of interspecific hybridization (Havelka et al. 2016), used in aquaculture (Chandra and Fopp-Bayat 2021). The probability of fact of interspecific hybridization is assumed since the second half of the 19th century when "crossbreeds" of A. ruthenus with the Fringebarbel sturgeon (A. nudiventris Lovetsky, 1828), Beluga (Huso huso Linnaeus, 1758), Siberian sturgeon, and Starry sturgeon (A. stellatus Pallas, 1771) were found (Berg 1911). Berg (1911) also noted that the hybrids of A. ruthenus and A. baerii are found everywhere where both of these species are present, in the $\mathrm{Ob}$ and the Yenisei Rivers, but these assumptions were based only on morphological features, thus there was no real evidence. However, we did not find the hybrids of sturgeons in this section of the river for the previous research period of 2012-2017. The researchers found that the ease of hybridization of sturgeons is noted both during artificial (Zhang et al. 2013) and natural reproduction (Ludwig et al. 2009), especially in the presence of natural hybrid zones (Allendorf et al. 2001; Jordan et al. 2019). In a laboratory, attempts are being made to use A. ruthenus as surrogate individuals - recipients to obtain the gonads of $A$. baerii used as a donor (Linhartová et al. 2015; Pšenička et al. 2015). This technology is applicable for the conservation and revival of the genetic resources of endangered and endemic species (P̌̌enička et al. 2015; Lujić et al. 2018). Anthropogenic impacts, such as habitat modification, a violation of hydrological parameters and a decrease in spawning areas, can reduce precopulation barriers and increase the contact of gametes of some species (Lagunova 1999; Chafin et al. 2019; Mandeville et al. 2019, Ramoejane et al. 2019) including sturgeons (Lagunova 1999; Dudu et al. 2011; Chafin et al. 2019; Seyoum et al. 2020).

The probability of hybridization among related species depends on the degree of reproductive isolation (Coyne and Orr 2004), which is supported by various precopulation barriers. For fish, this may be water temperature, spawning substrate, hydrological characteristics in spawning areas (Vasil'eva and Vasil'ev 2019). The reasons for the hybridization of fish are overlapping spawning periods and a no- 
ticeable difference in the number of individuals in co-inhabited biotopes (Vasil'eva, Vasil'ev 2019). An example of anthropogenic disturbance of the precopulation reproductive barrier that interferes with the hybridization of $A$. ruthenus and A. baerii is the hybridization of these species in the Danube River (Ludwig et al. 2009), as a result of the "escape" of some individuals of $A$. baerii from a fish breeding farm into a natural watercourse.

In the laboratory study of the hybridization of $A$. ruthenus and A. baerii based on molecular markers, it was established that when these species competed in mixed sperm, $78.9 \%$ of the offspring came from $A$. ruthenus and $21.1 \%$ from $A$. baerii that demonstrates a higher fertilization success of $A$. ruthenus (Havelka et al. 2016). In addition, the combined eggs were inseminated with sperm of $A$. ruthenus or A. baerii separately, the offspring was almost equally distributed between hybrid individuals and individuals of parental species (Havelka et al. 2016). It should be noted (Shaliutina et al. 2013; Shaliutina-Kolešová et al. 2015) that the speed of spermatozoa for males of $A$. ruthenus is lower than of $A$. baerii. However, there is another sign which can promote hybridization of $A$. ruthenus and $A$. baerii in mixed sperm with a predominance of hybrids from A. ruthenus (Havelka et al. 2016). This is the diameter of the head of spermatozoa, which is significantly lower in A. ruthenus than in A. baerii (Psenicka et al. 2008). This allows spermatozoa of $A$. ruthenus easier to penetrate into the cytoplasm of the egg than larger spermatozoa of $A$. baerii (Havelka et al. 2016). Therefore, in competition, spermatozoa of $A$. ruthenus can fertilize more eggs than spermatozoa of $A$. baerii. Thus, it was shown (Havelka et al. 2016) that there can be no post-copulation mechanisms preventing hybridization between $A$. ruthenus and $A$. baerii. In our research, both species, $A$. ruthenus and $A$. baerii, habitat a natural environment and not in isolation from each other, while their spawning sites do not intersect (Fig. 1). For A. baerii, it was established that its spawning grounds are located in the Irtysh River from the Tobolsk district of the Tyumen region to the city Tara, Omsk region (Bol'shakov et al. 2004), for A. ruthenus, it is downstream Tobolsk to the village Uki Tyumen Region (Tretyakova 2014). It has also been shown that these species have different preferences in the spawning substrate: for A. baerii, it is rocky-gravel or gravel-sandy soil, for A. ruthenus it is pebble-sandy soil (Reshetnikov 2003). There are also different preferences in the range of spawning temperatures: $9-21$ and $10-15^{\circ} \mathrm{C}$, respectively. Thus, the probability of contact by mature individuals of these fish species in spawning areas is minimal.

It is noted (Kodukhova 2011; Veshchev et al. 2012) that the level of the natural reproduction of fish is mainly determined by the water level and abundance of mature fish, under adverse hydrological conditions (low water and middle water levels years), spawning occurs in limited spawning areas. Therefore, low water levels in spawning areas are considered one of the factors of fish hybridization and apparently a factor for the formation of temporary hybrid zones (Kodukhova 2011; Veshchev et al. 2012). In extremely low water levels years, the productivity of sturgeons spawning grounds may decrease more than 2 times (Veshchev et al. 2012). It should 
be noted that the period of origin of the hybrids (2017) in terms of water level was statistically significantly higher than the average long-term level in all observed hydrological posts of the Irtysh River in the zone of spawning areas of A. baerii and A. ruthenus, including upstream and downstream of them (Fig. 5). This also allows us to exclude a small number of spawning sites as one of the factors of a natural hybridization of $A$. ruthenus and A. baerii in the Lower Irtysh River.

An analysis of the literature data demonstrates that the hybrids of $A$. ruthenus and $A$. baerii are not able to generate offspring (Linhartova et al. 2018) due to the fact that they are genetically distant species within the Acipenseriformes order (Peng et al. 2007; Krieger et al. 2008), having different chromosome number (Havelka et al. 2011) and a level of ploidy (Birstein et al. 1993). Acipenser baerii has a tetraploid set of chromosomes, $A$. ruthenus has the diploid set. The literature just describes that males can be fertile from hybrids of species with different ploidy, i.e. such male hybrid individuals can endanger the genetic stock of native purebred populations. This is also confirmed by studies conducted by Podushka in 2004 (Podushka 2004). Besides, the hybrids can compete with $A$. baerii and $A$. ruthenus for nutrition and wintering section (riverbeds depression). Hybridization is especially problematic for rare species that come into contact with other more numerous species (Allendorf et al. 2001; Borkin and Litvinchuk 2013). There is a waste of the reproductive efforts of the species. This is especially important for our study because A. baerii belongs to endangered species (Bol'shakov et al. 2004).

The reason for the frequent detection of fish hybrids can be both natural and unintentional anthropogenic changes in the habitats (Kodukhova 2011). In addition, random instances from fish farms cannot be excluded, which are usually sources of individuals of hybrid (Chelomina et al. 2008; Ludwig et al. 2009). It is worth noting that in the study area several fish-breeding organizations release the juvenile individuals of $A$. ruthenus and $A$. baerii into the Irtysh River and its tributary, the Tobol River, to compensate for damage caused to fisheries by anthropogenic activities. In this regard, our study confirms that the origin of the detected hybrids is considered anthropogenic. Factors contributing to interspecific hybridization of A. ruthenus and $A$. baerii in the habitats (Irtysh River) were absent during the study period: a reliably high water level that exceeded the long-term average was observed, spawning plots of species were remote, a small number of sturgeons was found due to their protection and the prohibition of all types of fishing, except for fishing for research.

\section{Conclusion}

Based on the analysis of the morphological and genetic characteristics of "atypical" specimens of sturgeon from the Irtysh River, as well as data on the hydrological situation of the study area, it is possible to suggest that the most probable scenario is the one based on the anthropogenic origin of these hybrids. At the same time, one should not consider the appearance of the hybrids in the Irtysh River trunk as an in- 
vasion of alien species that have several negative effects, up to disturbing ecosystem stability and environmental disasters; since they are sterile and their parent species are native to the Irtysh River ecosystem and not isolated from each other. This is the first recorded and described fact of the appearance of sturgeon hybrids in the $\mathrm{Ob}$ Irtysh basin based on complex analysis, including morphometric and genetic. It is necessary to continue monitoring studies to identify the number of these hybrids in the ecological system of the Irtysh River. The data set of morphological characters and genetic methods can be used to identify hybrids of $A$. ruthenus and A. baerii.

\section{Acknowledgments}

We are grateful to A. Vorob'eva, Tyumen State University, for laboratory assistance; V. Evdash, Center for Academic Writing "Impulse", Tyumen State University, Tyumen, for English assistance.

\section{References}

Allendorf FW, Leary RF, Spruell P, Wenburg JK (2001) The problems with hybrids: setting conservation guidelines. Trends in Ecology \& Evolution 16 (11): 613-622. https://doi. org/10.1016/s0169-5347(01)02290-x

Ardura A, Pola IG, Linde AR, Garcia-Vazquez E (2010) DNA-based methods for species authentication of Amazonian commercial fish. Food Research International 9: 2295-2302. https://doi.org/10.1016/j.foodres.2010.08.004

Atalah J, Sanchez-Jerez P (2020) Global assessment of ecological risks associated with farmed fish escapes. Global Ecology and Conservation. 21: e00842. https://doi.org/10.1016/j. gecco.2019.e00842

Barmintseva AE, Mugue NS (2017) Natural genetic polymorphism and phylogeography of the Siberian sturgeon Acipenser baerii Brandt, 1869. Russian Journal of Genetics 53 (3): 358-368. https://doi.org/10.1134/s1022795417030024

Barmintseva AE, Mugue NS (2018) Genetic variation of the Siberian sturgeon (Acipenser baerii Brandt, 1869) in aquaculture. Russian Journal of Genetics 54 (2): 210-217. https://doi.org/10.1134/s1022795418020035

Begum BD, Dharani G, Altaff K (2018) Molecular systematics of freshwater diaptomid species of the genus Neodiaptomus from Andaman Islands, India. Genetics of Aquatic Organisms 2: 13-22. https://doi.org/10.4194/2459-1831-v2_1_03

Bender W, Pierre S, Hognes DS (1983) Chromosomal walking and jumping to isolate DNA from ace and rosy loci of bithorax complex in Drosophila melanogaster. Journal of Molecular Biology 168: 17-33. https://doi.org/10.1016/s0022-2836(83)80320-9

Berg LS (1911) Fauna of Russia and adjacent territories. Fish, USSR Academy of Sciences, St. Petersburg, 366 pp. 
Birstein VJ, Poletaev AI, Goncharov BF (1993) DNA content in Eurasian sturgeon species determined by flow cytometry. Cytometry 14 (4): 377-383. https://doi.org/10.1002/ cyto.990140406

Bol'shakov VN, Bogdanov VD, Vasil'ev AG, Ishhenko VG, Magomedova MA, Morozova LM, Rjabicev VK (Eds.) (2004) The Red Data Book of the Tyumen region: animals, plants, mushrooms. Ural University Publishing House, Yekaterinburg, 496:

Borkin LYa, Litvinchuk SN (2013) Animal hybridization, speciation and systematics, Proceedings of the Zoological Institute 317 (2): 83-139.

Chafin TK, Douglas MR, Martin BT, Douglas ME (2019) Hybridization drives genetic erosion in sympatric desert fishes of western North America. Heredity 123 (6): 759-773. https://doi.org/10.1038/s41437-019-0259-2

Chandra G, Fopp-Bayat D (2021) Trends in aquaculture and conservation of sturgeons: a review of molecular and cytogenetic tools. Reviews in Aquaculture 13: 119-137. https:// doi.org/10.1111/raq.12466

Chassaing O, Hänni C, Berrebi P (2010) Distinguishing species of European sturgeons Acipenser spp. using microsatellite allele sequences. Journal of Fish Biology 78 (1): 208 226. https://doi.org/10.1111/j.1095-8649.2010.02852.x

Chebanov M, Podushka S, Rachek E, Amvrosov D, Merkulov Y (2018) Hybrids of the Siberian Sturgeon. In: The Siberian Sturgeon (Acipenser baerii, Brandt, 1869) Volume 2 - Farming: 289-326. https://doi.org/10.1007/978-3-319-61676-6_14

Chelomina GN, Rozhkovan KV, Ivanov SA (2008) Discrimination of interspecific hybrids in natural populations of Amur sturgeon fish using multilocus RAPD-PCR markers. Cytology and Genetics 42 (5): 61-71.

Coyne JA, Orr AH (2004) Speciation. Sinauer Associates, Inc., Sunderland, Massachusetts, USA, 545.

Dudu A, Suciu R, Paraschiv M, Georgescu SE, Costache M, Berrebi P (2011) Nuclear markers of danube sturgeons hybridization. International Journal of Molecular Sciences 12 (10): 6796-6809. https://doi.org/10.3390/ijms12106796

Fernandes TJR, Costa J, Beatriz MM, Oliveira PP, Mafra I (2017) DNA barcoding coupled to HRM analysis as a new and simple tool for the authentication of Gadidae fish species. Food Chemistry 230: 49-57. https://doi.org/10.1016/j.foodchem.2017.03.015

Gnedov AA, Kaizer AA (2013) Identification of fish species of the sturgeon family (Acipenseridae) caught in the Yenisei North. Siberian herald of agricultural science 3 (232): $84-90$.

Ha TTT, Thuy NTT, Van NS (2018) Identification of Fish in Semilabeo Genus Using Morphological Taxonomy and Molecular Biology Methods. Genetics of Aquatic Organisms 2: 23-28. http://doi.org/10.4194/2459-1831-v2_1_04

Havelka M, Kašpar V, Hulák M, Flajšhans M (2011) Sturgeon genetics and cytogenetics: a review related to ploidy levels and interspecific hybridization. Folia Zoologica 60 (2): 93-103. https://doi.org/10.25225/fozo.v60.i2.a3.2011

Havelka M, Šachlová H, Shaliutina-Kolešová A, Rodina M (2016) Fertilization success of sterlet Acipenser ruthenus and Siberian sturgeon Acipenser baerii gametes under condi- 
tions of heterospecific mating. Animal Reproduction Science 174: 107-113. https://doi. org/10.1016/j.anireprosci.2016.09.012

Hubbs C L (1955) Hybridization between fish species in nature. Systematic Zoology 4 (1): $1-20$.

Jordan GR, Heist EJ, Kuhajda BR, Moyer GR, Hartfield P, Piteo MS (2019) Morphological identification overestimates the number of Pallid sturgeon in the Lower Mississippi River due to extensive introgressive hybridization. Transactions of the American Fisheries Society 148 (5): 1004-1023. https://doi.org/10.1002/tafs.10194

Kafanova FF (1984) Methods for determining the age and growth of fish. Publishing house of Tomsk University, Tomsk, 128.

Káldy J, Káldy J, Mozsár A, Fazekas G, Farkas M, Fazekas DL, Fazekas GL, Goda K, Gyöngy Z, Kovács B, Semmens K, Bercsényi M, Molnár M, Patakiné Várkonyi E (2020) Hybridization of Russian Sturgeon (Acipenser gueldenstaedtii, Brandt and Ratzeberg, 1833) and American Paddlefish (Polyodon spathula, Walbaum 1792) and evaluation of their progeny. Genes 11(7): 753. https://doi.org/10.3390/genes11070753

Kodukhova YV (2011) Yearly variations of impact of natural hybrids of bream and roach (Abramis brama (L.) $\times$ Rutilus rutilus (L.)) in Rybinsk Reservoir. Russian Journal of Biological Invasions 2 (2-3): 204-208. https://doi.org/10.1134/s2075111711030076

Kottelat M, Freyhof J (2007) Handbook of European Freshwater Fishes. Publications Kottelat, Cornol-Berlin, 646.

Krieger J, Hett AK, Fuerst PA, Artyukhin E, Ludwig A (2008) The molecular phylogeny of the order Acipenseriformes revisited. Journal of Applied Ichthyology 24 (Suppl. 1): 36-45. https://doi.org/10.1111/j.1439-0426.2008.01088.x

Lagunova V (1999) The impact of conditions in the Volga River on hybridization, abnormal development and reproduction rate of sturgeons (Acipenseridae). Journal of Applied Ichthyology 15 (4-5): 291-291. https://doi.org/10.1111/j.1439-0426.1999.tb00275.x

Lima FP, de Frietas Mourão AA, Nobile AB, Freitas-Souza D, Foresti F, Oliveira C, Foresti FP (2019) Occurrence of serrassalmidae hybrid fish in the Amazon river basin, Brazil. Oecologia Australis 23 (01): 156-164. https://doi.org/10.4257/oeco.2019.2301.15

Linhartova Z, Havelka M, Pšenička M, Flajšhans M (2018) Interspecific hybridization of sturgeon species affects differently their gonadal development. Czech Journal of Animal Science 63 (1): 1-10. https://doi.org/10.17221/37/2016-cjas

Linhartová Z, Saito T, Kašpar V, Rodina M, Prášková E, Hagihara S, Pšenička M (2015) Sterilization of sterlet Acipenser ruthenus by using knockdown agent, antisense morpholino oligonucleotide, against dead end gene. Theriogenology 84 (7): 1246-1255.e1. https:// doi.org/10.1016/j.theriogenology.2015.07.003

Ludwig A, Lippold S, Debus L, Reinartz R (2009) First evidence of hybridization between endangered sterlets (Acipenser ruthenus) and exotic Siberian sturgeons (Acipenser baerii) in the Danube River. Biological Invasions 11: 753-760. https://doi.org/10.1007/ s10530-008-9289-Z

Lujić J, Marinović Z, Bajec SS, Djurdjevič I, Urbányi B, Horváth Á (2018) Interspecific germ cell transplantation: a new light in the conservation of valuable Balkan trout genetic re- 
sources? Fish Physiology and Biochemistry 44 (6): 1487-1498. https://doi.org/10.1007/ s10695-018-0510-4

Mallet J (2007) Hybrid speciation. Nature 446 (7133): 279-283. https://doi.org/10.1038/nature 05706

Mandeville EG, Walters AW, Nordberg BJ, Higgins KH, Burckhardt JC, Wagner CE (2019) Variable hybridization outcomes in trout are predicted by historical fish stocking and environmental context. Molecular Ecology 28 (16): 3738-3755. https://doi.org/10.1111/ mec. 15175

Mugue NS, Barmintseva AE, Rastorguev SM, Mugue VN, Barmintsev VA (2008) Polymorphism of the mitochondrial DNA control region in eight sturgeon species and development of a system for DNA-based species identification. Russian Journal of Genetics 44 (7): 793-798. https://doi.org/10.1134/s1022795408070065

Nyeste K, Somogyi D, Sallai Z, Antal L (2020) Recent occurrence data of sturgeons (Acipenseridae) in the Carpathian Basin. Pisces Hungarici 14: 107-114.

Parenskiy VA, Skirin VI, Romanov NS (2008) Analysis of the stability of the morphological appearance and heritability of traits during hybridization of sturgeon fishes. Transactions of the Pacific Research Institute of Fisheries and Oceanography 155: 230-249.

Peng Z, Ludwig A, Wang D, Diogo R, Wei Q, He S (2007) Age and biogeography of major clades in sturgeons and paddlefishes (Pisces: Acipenseriformes). Molecular Phylogenetics and Evolution 42 (3): 854-862. https://doi.org/10.1016/j.ympev.2006.09.008

Pravdin IF (1966) Guide to the study of fish. Food industry, Moscow, 146.

Pobedintseva MA, Makunin AI, Kichigin IG, Kulemzina AI, Serdyukova N A, Romanenko SA, Trifonov VA (2019) Population genetic structure and phylogeography of sterlet (Acipenser ruthenus, Acipenseridae) in the $\mathrm{Ob}$ and Yenisei river basins. Mitochondrial DNA. Part A 30 (1): 156-164. https://doi.org/10.1080/24701394.2018.1467409

Podushka SB (2004) Are "sterile hybrids of sturgeon" sterile. Aquaculture of sturgeon fish: achievements and prospects of development. Proceedings of 3rd International research and practical conference. "Alfa-Ast", Astrakhan, 202-203.

Porto-Foresti F, Hashimoto DT, Prado FD, Senhorini JA, Foresti F (2013) Genetic markers for the identification of hybrids among catfish species of the family Pimelodidae. Journal of Applied Ichthyology 29 (3): 643-647. https://doi.org/10.1111/jai.12092

Psenicka M, Hadi Alavi SM, Rodina M, Cicova Z, Gela D, Cosson J, Linhart O (2008) Morphology, chemical contents and physiology of chondrostean fish sperm: a comparative study between Siberian sturgeon (Acipenser baerii) and sterlet (Acipenser ruthenus). Journal of Applied Ichthyology 24 (4): 371-377. https://doi.org/10.1111/j.14390426.2008.01139.x

Pšenička M, Saito T, Linhartová Z, Gazo I (2015) Isolation and transplantation of sturgeon early-stage germ cells. Theriogenology 83 (6): 1085-1092. https://doi.org/10.1016/j.theriogenology.2014.12.010

Ramoejane M, Gouws G, Swartz E R, Sidlauskas B L, Weyl O L F (2019) Molecular and morphological evidence reveals hybridisation between two endemic cyprinid fishes. Journal of Fish Biology 96 (5):1234-1250. https://doi.org/10.1111/jfb.14153

Reshetnikov YuS (2003) Atlas of Russian freshwater fishes, Science, Moscow. 348. 
Rozhkovan KV, Chelomina GN, Rachek EI (2008) Molecular identification and the features of genetic diversity in interspecific hybrids of Amur sturgeon (Aeipenser sehrenekii $\times$ A. baerii, A. baerii $\times$ A. sehrenekii, A. sehrenekii $\times$ A. ruthenus and A. ruthenus $\times A$. sehrenekii) based on variability of multilocus RAPD markers. Russian Journal of Genetics 44 (11):1258-1265. https://doi.org/10.1134/s1022795408110021

Sales NG, Pessali TC, Andrade Neto FR, Carvalho DC (2018) Introgression from non-native species unveils a hidden threat to the migratory Neotropical fish Prochilodus hartii. Biological Invasions 20 (3): 555-566. https://doi.org/10.1007/s10530-017-1556-4

Schwenk K, Brede N, Streit B (2008) Introduction. Extent, processes and evolutionary impact of interspecific hybridization in animals. Philosophical Transactions of the Royal Society. B. Biological Sciences 363: 2805-2811. https://doi.org/10.1098/rstb.2008.0055

Seyoum S, Adams DH, Matheson RE, Whittington JA, Alvarez AC, Sheridan NE, Puchulutegui C (2020) Genetic relationships and hybridization among three western Atlantic sparid species: sheepshead (Archosargus probatocephalus), sea bream (A. rhomboidalis) and pinfish (Lagodon rhomboides). Conservation Genetics 21 (1): 161-173. https://doi. org/10.1007/s10592-019-01244-7

Shaliutina A, Hulak M, Gazo I, Linhartova P, Linhart O (2013) Effect of short-term storage on quality parameters, DNA integrity, and oxidative stress in Russian (Acipenser gueldenstaedtii) and Siberian (Acipenser baerii) sturgeon sperm. Animal Reproduction Science 139 (1-4): 127-135. https://doi.org/10.1016/j.anireprosci.2013.03.006

Shaliutina-Kolešová A, Cosson J, Lebeda I, Gazo I, Shaliutina O, Dzyuba B, Linhart O (2015) The influence of cryoprotectants on sturgeon (Acipenser ruthenus) sperm quality, DNA integrity, antioxidant responses, and resistance to oxidative stress. Animal Reproduction Science 159: 66-76. https://doi.org/10.1016/j.anireprosci.2015.05.014

Shedko SV, Miroshnichenko IL, Nemkova GA, Koshelev VN, Shedko NB (2015) Mitochondrial DNA sequence variation, demographic history, and population structure of Amur sturgeon Acipenser schrenckii Brandt, 1869. Russian Journal of Genetics 51 (2): 169-184. https://doi.org/10.1134/s102279541502012x

Shishanova EI (2013) Use of genetic-biochemical signs at certification of sturgeon fishes. Zootechniya 2: 6-7.

Smith GR (1992) Introgression in fishes: significance for paleontology, cladistics, and evolutionary rates. Systematic Biology 41 (1): 41-57. https://doi.org/10.1093/sysbio/41.1.41

Sriphairoj K, Na-Nakorn U, Klinbunga S (2018) Species identification of non-hybrid and hybrid Pangasiid catfish using polymerase chain reaction-restriction fragment length polymorphism. Agriculture and Natural Resources 52 (1): 99-105. https://doi.org/10.1016/j. anres.2018.05.014

Timoshkina NN, Vodolazhskii DI, Usatov AV (2011) Molecular-genetic markers in studies of intra- and interspecies polymorphism in sturgeon (Acipenseriformes). Russian Journal of Genetics: Applied Research 1: 160-171. https://doi.org/10.1134/s2079059711020122

Tretyakova TV (2014) Seasonal distribution of Siberian sterlet in the Tobolsk-Uvat section of the Irtysh River. Natural and mathematical sciences in the modern world 24: 140-144. 
Uemura Y, Yoshimi S, Hata H (2018) Hybridization between two bitterling fish species in their sympatric range and a river where one species is native and the other is introduced. Plos one 13 (9): e0203423. https://doi.org/10.1371/journal.pone.0203423

Vasil'eva ED, Vasil'ev VP (2019) Natural hybridization in spined loaches of the genera Cobitis and Sabanejewia (Cobitidae). Journal of ichthyology 59 (5):776-785. https://doi. org/10.1134/s0032945219050163

Veshchev PV, Guteneva GI, Mukhanova RS (2012) Efficiency of natural reproduction of sturgeons in the lower Volga under current conditions. Russian Journal of Ecology 43 (2): 142-147. https://doi.org/10.1134/s1067413612020154

Zhang X, Wu W, Li L, Ma X, Chen J (2013) Genetic variation and relationships of seven sturgeon species and ten interspecific hybrids. Genetics Selection Evolution 45: 21. https:// doi.org/10.1186/1297-9686-45-21 